\title{
Vertical Crustal Motion along the Mediterranean and Black Sea Coast derived from Ocean Altimetry and Tide Gauge Data
}

\author{
D. GARCÍA ${ }^{1}$, I. VIGO ${ }^{1}$, B. F. CHAO ${ }^{2}$ and M. C. MARTÍNEZ ${ }^{1}$
}

Abstract - Tide gauge (TG) data along the northern Mediterranean and Black Sea coast are compared to the sea surface height (SSH) anomaly obtained from ocean altimetry (TOPEX/Poseidon and ERS-1/2) for a period of 9 years, 1993-2001. The TG measures the SSH relative to the ground whereas the altimetry does so with respect to the geocentric reference frame; therefore their difference would be in principle a vertical ground motion of the TG sites, though there is different error sources for this estimate as is discussed in the paper. In this study we estimate such vertical ground motion, for each TG site, from the slope of the SSH time series of the (non-seasonal) difference between the TG record and the altimetry measurement at a point closest to the TG. Where possible, these estimates are further compared with those derived from nearby continuous Global Positioning System (GPS) data series. These results on vertical ground motion along the Mediterranean and Black Sea coast provide useful source data for studying, contrasting, and constraining tectonic models of the region. For example, in the eastern coast of the Adriatic Sea and in the western one of Greece, a general subsidence is observed which may be related to the Adriatic lithosphere subducting beneath the Eurasian plate along the Dinarides fault.

Key words: Mediterranean and Black seas, sea level, altimetry, tide gauge, vertical crustal motion, continuous GPS.

\section{Introduction}

Understanding the sea level variations is a complex interdisciplinary scientific challenge, for which a first step is to monitor the sea level change. For many decades, some of the most reliable and useful data series available are the sea level records taken at tide gauges (TG) at many places along the world's continental as well as island coasts. In the space age, to complement these observations and to acquire a

\footnotetext{
${ }^{1}$ Space Geodesy Laboratory, Department of Applied Mathematics, University of Alicante, Alicante, Spain

${ }^{2}$ College of Earth Sciences, National Central University, Chung-li, Taiwan, ROC
} 
more complete view of the open ocean, the technique of satellite altimetry was implemented and has seen great success ever since the Seasat mission in 1978. In this study we use altimetry data from a merged solution from European Remote Sensing 1-2 (ERS-1, 1991 - 1996; ERS-2, 1996 - Present) of European Space Agency (ESA), and the U.S. - French TOPEX/Poseidon (T/P, 1992 - 2005). T/P has achieved an unprecedented accuracy at $2-3 \mathrm{~cm}$, and its follow-on mission Jason-I (2002 - Present) is seeking the $1 \mathrm{~cm}$ accuracy [LUTHCKE et al., 2003].

The altimetry measurement of the sea surface height ( $\mathrm{SSH}$ ) consists of (i) the precise satellite location in relation to a reference ellipsoid, and (ii) the height of satellite over the surface measured by means of laser or radar pulses sent from the satellite and bounced back from the target surface. The difference between the two thus gives the SSH relative to the reference ellipsoid at the given location and time. In this sense the altimetry measurement gives the absolute geocentric SSH in the terrestrial reference frame.

On the other hand, the TG measurement gives the SSH relative to the solid ground on which the TG is fixed. Hence any vertical ground motion, for whatever reasons, will masquerade as an apparent sea level variation: An apparent sea level rise would be added to the absolute sea level motion as the land sinks, and conversely. Therefore, in principle the difference between the two data types, altimetry and TG, is the absolute vertical ground motion [CAZENAVE et al., 1999; NEREM and MITCHUM, 2002]. Let TG(t) denote the time series of the TG record of $\mathrm{SSH}$, and $\mathrm{Alt}(\mathrm{t})$ be that measured by altimetry at the closest available point to the TG site. Ideally, apart from measurement noise and the fact that the actual locales are not exactly the same (especially when coastal geometry influences are significant), Alt $(\mathrm{t})$ and $\mathrm{TG}(\mathrm{t})$ should be found to fluctuate in unison, with the only difference being the actual vertical motion at the TG site. At places where this motion is known or negligible, these sites have been the basis for the in-situ calibration/validation for altimetric measurements [CHAMBERS et al., 1998; MITCHUM 1994, 1998, 2000]. In this paper we will form the difference time series Alt(t)-TG(t) and examine its long-term behaviour on at least decadal timescales, where the local/geographic differences become less important and the effect of measurement noise can also be greatly reduced. It is hoped that a decade long record of $\operatorname{Alt}(\mathrm{t})-\mathrm{TG}(\mathrm{t})$ should be able to give unequivocal information about the long-term vertical ground motion in the absolute sense. We will not be concerned about timescales shorter than interannual and seasonal periods, for which Alt $(t)-T G(t)$ signifies primarily the surface mass loading effects on the ground, both tidal and non-tidal.

We shall estimate the linear trend, or slope, of the $\operatorname{Alt}(\mathrm{t})-\mathrm{TG}(\mathrm{t})$ record for each of the available $\mathrm{TG}$ 
locations along the northern coast of the Mediterranean Sea and the Black Sea. In this region, the postglacial rebound effect in the vertical ground motion is minimal according to geophysical models, around $\pm 0.1 / 0.2 \mathrm{~mm} /$ year [PELTIER, 2001], so our result reflects the vertical ground motion arising primarily from tectonics, except at the sites where local "noises" are evident, for example ground subsidence due to land settlement or groundwater extraction. This provides for regional tectonics studies source information that is independent of, and complementary to, other data types such as gravity and GPS. In fact, the series of vertical motion recorded at various continuous GPS stations will be compared with our results for further insight.

\section{Data}

Figure 1 shows the locations of all data used in this study as described below. The numbering of the TG sites, which is in the west-to-east order along the coast, corresponds to the numbering in Table 1; the same goes with the GPS stations with respect to Table 2 . The altimetry grid points are indicated by the dots; those closest to each TG are indicated by the larger dots.

\subsection{Altimetry Data}

The altimetry data used in this study are monthly Sea Level Anomalies (SLA) maps, on a $1^{\circ}$ by $1^{\circ}$ grid, solved from the ocean radar altimetry data from satellite missions of T/P [FU and CAZENAVE, 2001] and ERS-1/2 for a 9-year period of 01/1993 - 12/2001. Data are a combination of T/P+ERS, except for the period 01/1994 - 03/1995 (ERS-1 geodetic phase). These gridded multimission data have been used, opposed to using the along track data from one single satellite, because of its higher accuracy and resolution. SLA are given in units of mm, where a 7-year (01/1993 - 01/1999) T/P data representing the static geoid is removed from the altimeter data. There are about 310 grid points in the Mediterranean and about 61 grid points in the Black Sea. Several corrections have been applied to the data: orbit error reduction of ERS via the precise orbit of T/P, geophysical (dry and wet troposphere, ionosphere and inverse barometer effect), sea state bias and tides (ocean and load tides, solid earth tide and pole tide). For further details see AVISO $(1996 ; 1998)$. Whether one should allow inverse barometer (IB) correction or not in this case is debatable as it was noted that IB is not prevalent for the Mediterranean Sea at relatively short periods (LE TRAON and 
GAUZELIN, 1997); we here use IB corrected data as we are interested in long-period variations.

The region we examine for the Mediterranean and Black seas is between 5EW and 42EE in longitude, $30 \mathrm{EN}$ and $48 \mathrm{EN}$ in latitude. We choose the altimetry measurement at the closest point to the tide gauge as stated.

\subsection{Tide Gauge Data}

In this study we use TG data available from the Permanent Service for Mean Sea Level (PSMSL) [SPENCER and WOODWORTH, 1993]. For the present study we choose, for 42 gauges along the northern coast of Mediterranean and 7 along the Black Sea coast, the so-called RLR (Revised Local Reference) series that provide precise information about the TG benchmark. Data are monthly time series that cover most of the 9-year altimeter period of this study. When needed, data gaps in the TG data series are linearly interpolated to facilitate data processing.

Barring some limited earlier TG activities in Egypt (pre-dating our study period), no data are available from the southern coast of Mediterranean. Neither are the many TG records from the Italian peninsula reported to PSMSL in recent years [TSIMPLIS and SPENCER, 1997] (but see [FENOGLIO-MARC et al., 2004] for analysis of the Italian records). Otherwise, the spatial distribution of the TG that we use (those with data after 1993 in PSMSL) is quite dense and homogeneous along the Mediterranean and Black Sea coasts, as shown in Figure 1.

\section{Analysis and Results}

It is clear that all the data series above are dominated by very strong seasonal signals, primarily annual and semiannual. There are of course various meteorological as well as geophysical reasons why this is so, but whatever the reasons, they are outside of our present interest. It is thus desirable to remove the seasonal signals from our data series, as their presence would skew our later estimates in various ways and render our statistics intractable due to the strong departure from broad-band or "white" statistics.

We remove the seasonal signals (annual and semiannual) from the original time series by simple subtraction of estimates obtained by least-squared fitting of seasonal sinusoids with annual and semiannual periods. We then compare the altimetry observed SSH anomaly, Alt $(\mathrm{t})$, at the closest grid point to a TG 
location with the given $\mathrm{TG}(\mathrm{t})$. The chosen altimetry point is just the closest one to the TG and it can be as far $\sqrt{2}$ as

2 degrees. The difference between them, which can be estimated from the altimetry point locations in Figure 1 and the TG ones in Table 1, and the coastal geometry of each TG have not been taken into account on the computations and they are considered as a source of error. The corrections applied to the altimetry data are made over the orbit groundtrack of the satellites, some of them are highly dependent of measurements taken along-track by other instruments onboard the satellite, and most of them were developed to be applied in the open ocean. Some of those corrections present problems in the coast, and for that reason, they cannot be easily applied to TG measurements. The resolution of those problems and the implementation of the altimetry corrections in the TG data need further studies and are beyond the scope of this paper. Then, the different corrections applied to each data represent another source of error. Nevertheless, a general good agreement can be observed between the two time series, showing a same temporal behaviour in much of the SSH fluctuations. In particular, for example, in VIGO et al. (2005) a prominent and abrupt change in the slope of the Mediterranean and Black Sea SSH during 1999 was found to exist in both $\mathrm{Alt}(\mathrm{t})$ and $\mathrm{TG}(\mathrm{t})$. However, when examining the long-term behaviour of $\mathrm{SSH}$, discrepancies between the two, which are our sought signal, arise. In Figure 2, three examples of such comparison are shown, -- Marseille and Trieste in the Mediterranean, and Tuapse in the Black Sea. The time series on the left are the original observation data from the two sources; the middle column those after the removal of the nominal seasonal signals as just described. The right column shows the respective non-seasonal $\operatorname{Alt}(\mathrm{t})-\mathrm{TG}(\mathrm{t})$ difference series. As stated, a TG measures the SSH relative to the ground on which the TG sits, whereas the altimetry measures the absolute SSH relative to the terrestrial reference frame with respect to which the satellite orbit is defined. Their difference then contains all information about the vertical ground motion of the tide gauge location in the terrestrial frame. We form the (non-seasonal) Alt $(\mathrm{t})-\mathrm{TG}(\mathrm{t})$ for the 49 PSMSL TG sites as described above and estimate their slopes using least-squares linear fit - a positive slope means land uplift while a negative slope land subsidence. Such linear slopes are plotted in the right columns of Figure 2.

Table 1 shows our estimates for the Alt $(\mathrm{t})-\mathrm{TG}(\mathrm{t})$ linear slopes for all stations. Positive values are in red (land up-lift), negative values in blue (land subsidence), while uncolored indicates values statistically indistinguishable from zero within 1 standard deviation (given in the last column). Figure 3 gives a map view of the same results as Table 1, where the "up" triangles represent land uplift, the "down" triangles 
represent land subsidence, circle means indistinguishable from zero, all color-scaled. It is seen that, except for a few near-zero ones and those that are known to have large local influences, the uplift-subsidence has definite spatial grouping, signifying regional patterns that are most likely of tectonic origin. This will be discussed below.

Several error sources are considered in estimating vertical land movements from the Alt-TG time series. For instance, we compare SSH at geographical points that are not exactly the same location but they are the closest grid point where the seasonal and shorter responses can be significantly different depending on the coastal geometry. Also, corrections for the solid-Earth and ocean tides, solid-Earth pole tides, and the equilibrium inverted barometer effects are all applied in the altimetry data, but not in the TG data. However, errors due to such differences are insignificant as far as the long-term trend is concerned and in any case small in magnitude. On the other hand, errors have been made also in the preparation and processing of data. Some gaps in the TG data were interpolated over; that if not treated in an optimal way could somewhat skew the slope estimates. Further errors come from the secular drift of the T/P instruments (altimeter as well as radiometer for atmospheric correction) although such drifts have been corrected to the extent possible by the T/P Projects based on in-situ calibrations [RUF, 2000; KEIHM et al., 2000]. These error sources mainly impact our estimates of the vertical land movement that are close to zero, which we have indicated in our results.

For gaining more insight and for further validation we can compare our linear trend estimates for the vertical ground motion derived from $\operatorname{Alt}(\mathrm{t})-\mathrm{TG}(\mathrm{t})$ with corresponding data from permanent, continuous GPS stations that are reasonably nearby in location to the TG stations. About 150 GPS stations from the EUREF Permanent Network (EPN), distributed over 32 European countries, acquire high quality GPS data in near real-time. In particular we use the cleaned GPS time series for 22 stations, close to the TG (Figure 1), produced by the EPN Time Series Monitoring Project [A. KENYERES, personal communication, 2005]. These GPS time series did not start until late 1990s or early 2000s, so they generally only have limited overlap with the available TG data. For that reason, we only use the GPS data (till late 2002) in a rudimentary comparison with respect to the sign of the vertical velocity, where a general good agreement in sign is observed. This result is shown in Figure 3, whereas the numerical values are given in Table 2.

We also compared our linear trend estimates for the vertical ground motion with those obtained via several GPS campaigns from the SELF projects during the years 1993 - 1998 as reported by BECKER et al. [2002]. We note the following: (i) Becker et al. found no significant vertical motion in Spain, whereas our 
Alt $(t)-T G(t)$ result at face value indicates a coastal subsidence in Southern Spain. The reason is presently unclear (but see Section 4). (ii) Becker et al. reported a slight uplift at Venice and a subsidence at Trieste in Italy, whereas we found no significant motion at both sites. (iii) In Greece, a general agreement is observed at Kalamai, Katakolon, Patrai, Preveza, Rodhos and Iraklion where subsidence is reported, unlike the disagreement at Soudhas and Alexandroupolis where we found uplift, and at Siros where we found no significant motion with little TG data available. (iv) In the Black Sea, a good agreement in subsidence is found at Varna and Bourgas.

\section{Discussions and Conclusions}

The absolute rates of vertical ground motion obtained in this work (Figure 3 and Table 1) are in accordance with the general notion that the Mediterranean is a location of plate subduction boundary, and the seismicity is more active in the eastern Mediterranean and gets quieter towards the north. Here in order to establish the framework to draw farther conclusions, we need to delve deeper into the complexity of the Mediterranean tectonics. Prior to that, however, we should assess the impact of the glacial isostatic adjustment (GIA) on the vertical ground motion. Model of GIA by PELTIER [2001] puts the vertical ground motion at around $\pm 0.1 / 0.2 \mathrm{~mm} /$ year in the Mediterranean and Black Sea region. That amounts to just a small fraction of the land uplift/subsidence rates reported here. Thus, the vertical ground motion due to GIA does add to or subtract from the otherwise tectonic ground motion detected in our results, but the magnitude of that "contamination" is relatively small and has generally little, if any, impact on the sign of our results. Therefore we shall ignore the GIA influence in the discussion on tectonics below.

Figure 4 depicts the main tectonic processes in the Mediterranean and Black Seas. In the Mediterranean the collisions between the African, Eurasian and Arabic plates have produced a very complex tectonic regime of microplates that is far from resolved, especially with respect to vertical motions [R. SABADINI, H. DREWES, personal communication, 2003]. Some of the present plate boundaries, especially in the eastern Mediterranean, appear to be so diffuse and so anomalous that they cannot be categorized into the three classical types of plate boundaries - subduction, spreading, and transform. The global tectonic model NUVEL1 [DEMETS et al., 1990] and geodetic data establish that the Eurasian and African plates converge along NW-SE direction, both rotating anticlockwise [JIMENEZ-MUNT et al., 2003].

Being one of the most seismically active and rapidly deforming continental regions in the world, the 
Aegean Sea area in the eastern Mediterranean should be taken in special consideration. In this area, including western Turkey and Greece, many destructive earthquakes have occurred throughout history. The Crete island situates in the north side of the Hellenic Arc, which is the result of the ongoing collision between the African and Eurasian plates, causing Anatolian plate (Turkey) to move westward [McKENZIE, 1972; JIMENEZ-MUNT and SABADINI, 2002]. As a result, the African block is subducted northward, producing an uplift in Crete island [RAHL et al., 2004], which is in agreement with our results found in Soudhas, but not in Iraklion.

A general and distinct land subsidence in the west coast of Greece and the east coasts of the Adriatic Sea, is reported in this study. This finding may be related to the Adriatic lithosphere subducting beneath the Eurasian plate along the Dinarides fault (Figure 4). In particular, although Venice has seen geological evidences of subsidence (due to the rollback of the Apennines subduction, the contemporary effect of the load of the Alpine belt on its foreland and the river sediments, and the exploitation of subsurface water) [RUTIGLIANO et al., 2000], neither this study or BECKER et al. [2002] show such a subsidence. Then, further studies are needed to clarify this discrepancy. Similarly, the uplift in the eastern coast of Greece may be explained as a consequence of the same but converse associated movements.

On the other hand, we find conflicting behaviour (in terms of uplift versus subsidence) in the TGs located on the eastern (Turkish) coast of the Aegean Sea. It is unclear whether or how much of it is due to data errors, local motions, or any interesting regional tectonics. This awaits further studies. Similarly, towards the west, noteworthy is the fact that our study reflects opposite behaviour in the case of Sete and Marsella, France. Given their geographical proximity and if the results are correct, it might indicate the existence of a tectonic fault separating the two sites, although the exact location might not be clearly identified.

Finally, the western Mediterranean basins are almost totally surrounded by mountain belts that for the most part remain tectonically and seismically active. The three sub-basins of different ages reflect different stages in the development of the western Mediterranean by back-arc spreading in response to subduction of the African lithosphere beneath southern Europe. Our finding that the general area in southern Spain is subsiding is in odds with this subducting African plate model because such subduction should predict an uplift for the region. This appears quite interesting, but we should note that in the case of Alicante our estimate is strongly contaminated by the settling of the harbour construct on which the TG is situated. An individualized study for each TG should be done to identify additional or similar sources of error. 
However, such a study is beyond the scope of this work.

In summary, in spite of several error sources in the Alt-TG series, with a sufficiently long time span up to 9 years we are able to obtain reliable estimates for the vertical ground motion at the TG sites along the northern Mediterranean and Black Sea coast. These results provide useful source data for studying, contrasting, and constraining tectonic models of the region.

\section{Acknowledgments}

We are grateful for the organizations that provided the source data used here, including NASA Ocean Altimeter Pathfinder Project, the Permanent Service for Mean Sea Level, and EPN time series monitoring project, and for I. Jimenez-Munt that provided figure 4. We have also benefited from discussions with H-P.

Plag, S. Zerbini, and software assistance from A. Au. This work is supported by Spanish Science and Technology Ministery (Project ESP2001-4533-PE, Project ESP2005-xxxx), and NASA's Physical Oceanography Program.

\section{REFERENCES}

AVISO User Handbook: Merged Topex/Poseidon Products, AVI-NT-02-101-CN, Edition 3.0, July 1996. Online available from $<\mathrm{http}: / / \mathrm{www}$.jason.oceanobs.com/ $>$.

AVISO, User Handbook: Sea Level Anomalies, AVI-NT-011-312-CN, Edition 3.1, April 1998. Online available from $<$ http://www.jason.oceanobs.com/ $>$.

BECKER, M., ZERBINI, S., BAKER, T., BRKI, B., GALANIS, J., GARATE, J., GEORGIEV, I., KAHLE, H.-G., KOTZEV, V., LOBAZOV, V., MARSON, I., NEGUSINI, N., RICHTER, B., VEIS, G., YUZEFOVICH., P. (2002), Assessment of height variations by GPS at Mediterranean and Black Sea coast tide gauges from the SELF projects, Global and Planetary Change 34, 5-35.

CAZENAVE, A. et al. (1999), Sea level changes from Topex-Poseidon altimetry and tide gauges, and vertical crustal motions from DORIS. Geophys. Res Lett, 26, 2077-2080.

CHAMBERS, D. P., RIES, J. C., SHUM, C. K., TAPLEY, B. D. (1998), On the use of tide gauges to determine altimeter drift, J. Geophys. Res., 103 (C6), 12,885-12,890. 
DEMETS, C., R.G. GORDON, D.F. ARGUS \& S. STEIN (1990), Current plate motions. Geophysical Journal International, 101, 425-478.

FENOGLIO-MARC, L., DIETZ., L., GROTEN, E. (2004), Vertical Land Motion in the Mediterranean Sea from Altimetry and Tide Gauge Stations, Marine Geodesy, 27, 1-19.

JIMENEZ-MUNT, I., and SABADINI, R. (2002), The block-like behavior of Anatolia envisaged in the modeled and geodetic strain rates, Geophys. Res. Lett., 29(20), 1978, doi:10.1029/2002GL015995

JIMENEZ-MUNT, I., SABADINI, R., GARDI, A., and BIANCO, G., (2003), Active deformation in the Mediterranean from Gibraltar to Anatolia inferred from numerical modeling and geodetic and seismological data, J. Geophys. Res., 108(B1), 2006, doi:10.1029/2001JB001544.

KEIHM, S. J., ZLOTNIKI, V., and C.S. RUF, C. S. (2000), TOPEX Microwave Radiometer Performance Evaluation,1992-1998, IEEE Trans. Geosci. Remote Sensing, Vol. 38, pp. 1396-1386.

LE TRAON, P., and P. GAUZELIN. 1997. Response of the Mediterranean mean sea level to atmospheric pressure forcing, J. Geophys. Res., 102(C1), 973-984.

LUTHCKE, S. B., ZELENSKY, N. P., ROWLANDS, D. D., LEMOINE, F. G., WILLIAMS, T. A. (2003), The 1-Centimeter Orbit: Jason-1 Precision Orbit Determination Using GPS, SLR, DORIS, and Altimetry Data, Marine Geodesy, 26, 399-421.

McKENZIE, D.P. (1972), Active tectonics of the Mediterranean region. Geophysical Journal of the Royal Astronomical Society 30, 109-185.

MITCHUM, G.T. (1994), Comparison of TOPEX sea surface heights and tide gauge sea levels, J. Geophys. Res., 99, 24,541-24,553.

MITCHUM, G.T. (1998), Monitoring the stability of satellite altimeters with tide gauges, J. Atmos. Oceanic Tech., 15, 721-730.

MITCHUM, G.T. (2000), An improved calibration of satellite altimetric heights using tide gauge sea levels with adjustment for land motion, Marine Geodesy, 23, 145-166.

NEREM, R. S., MITCHUM, G. T. (2002), Estimates of vertical Crustal Motion Derived from Differences of TOPEX/Poseidon and Tide Gauge Sea Level Measurements, Geophys. Res. Lett., Vol 29, Iss 19, art. no. 1934.

PELTIER, W.R. (2001), ICE4G (VM2) Glacial Isostatic Adjustment Corrections, in Sea Level Rise; History and Consequences, Douglas, B.C., Kearney, M.S., and S.P. Leatherman (Eds.), Academic Press, etc.

RAHL, J. M., FASSOULAS, C., BRANDON, M. T. (2004), Exhumation of high-pressure metamorphic 
rocks within an active convergent margin, Crete, Greece: A field guide, 32th International Geological Congress, Vol. 2 - from B16 to B33, art. No B32.

RUF, C.S. (2000), Detection of calibration drifts in spaceborne microwave radiometers using a vicarious cold referenc,. IEEE Trans. Geosci. Remote Sensing, vol 38, pp 44-52.

RUTIGLIANO P., FERRARO C., DEVOTI R., LANOTTE R., LUCERI V., NARDI A., PACIONE R., SCIARRETTA C. (2000), Vertical motions in the Western Mediterranean area from geodetic and geological data, in the proceedings of The Tenth General Assembly of the Wegener Project.

SPENCER, N. E. AND WOODWORTH, P. L. (1993), Data Holdings of the Permanent Service for Mean Sea Level, Bidston, Birkenhead: Permanent Service for Mean Sea Level. 81pp.

TSIMPLIS, M. N., AND SPENCER, N. E. (1997), Collection and Analysis of Monthly Mean Sea Level Data in the Mediterranean and Black Sea, Journal of Coastal Research, 13, 2, 534-544, Fort Lauderdale, Florida.

VIGO, I., GARCÍA, D., AND CHAO, B. F. (2005), Change of sea level trend in the Mediterranean and Black seas, Journal of Marine Research, Vol. 63, N. 6. 


\section{FIGURES}

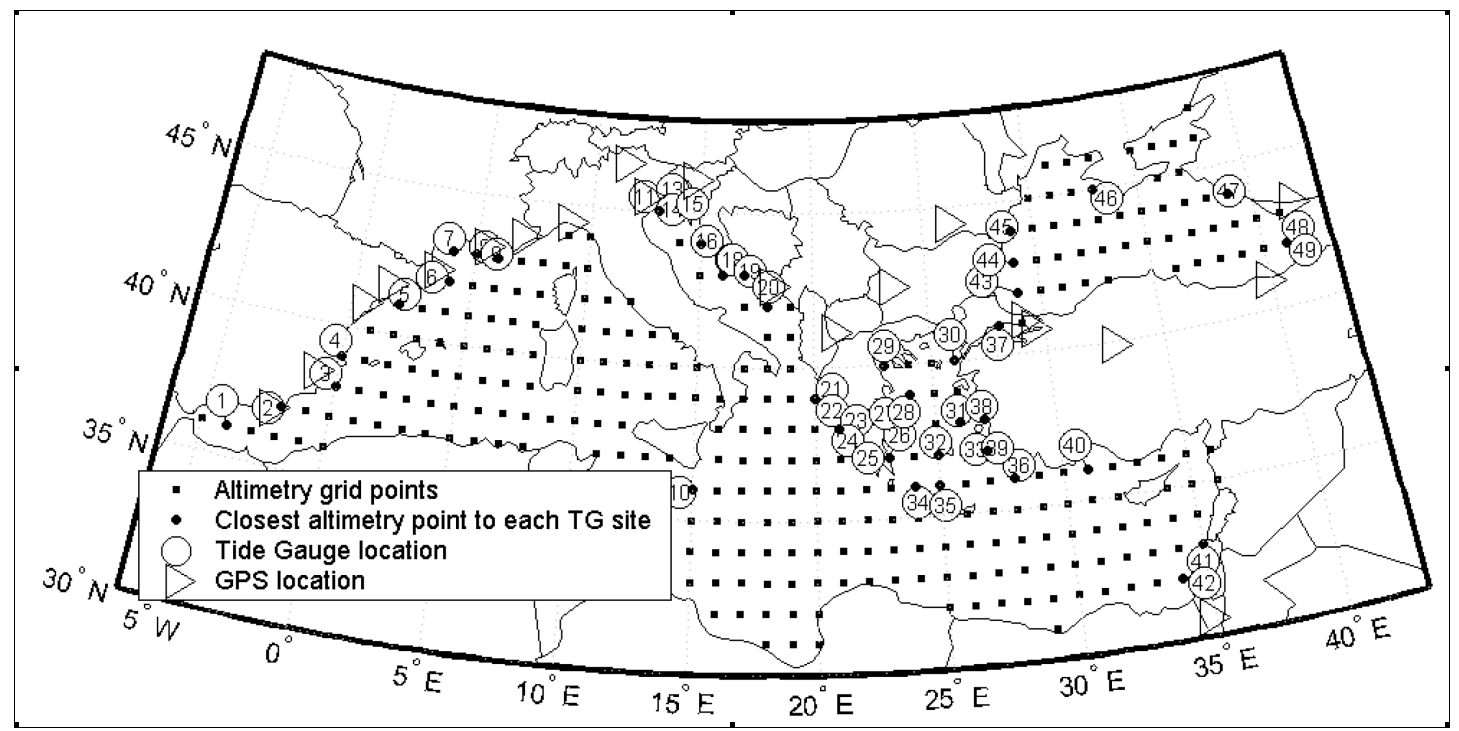

Figure 1. Data locations used in this study. 

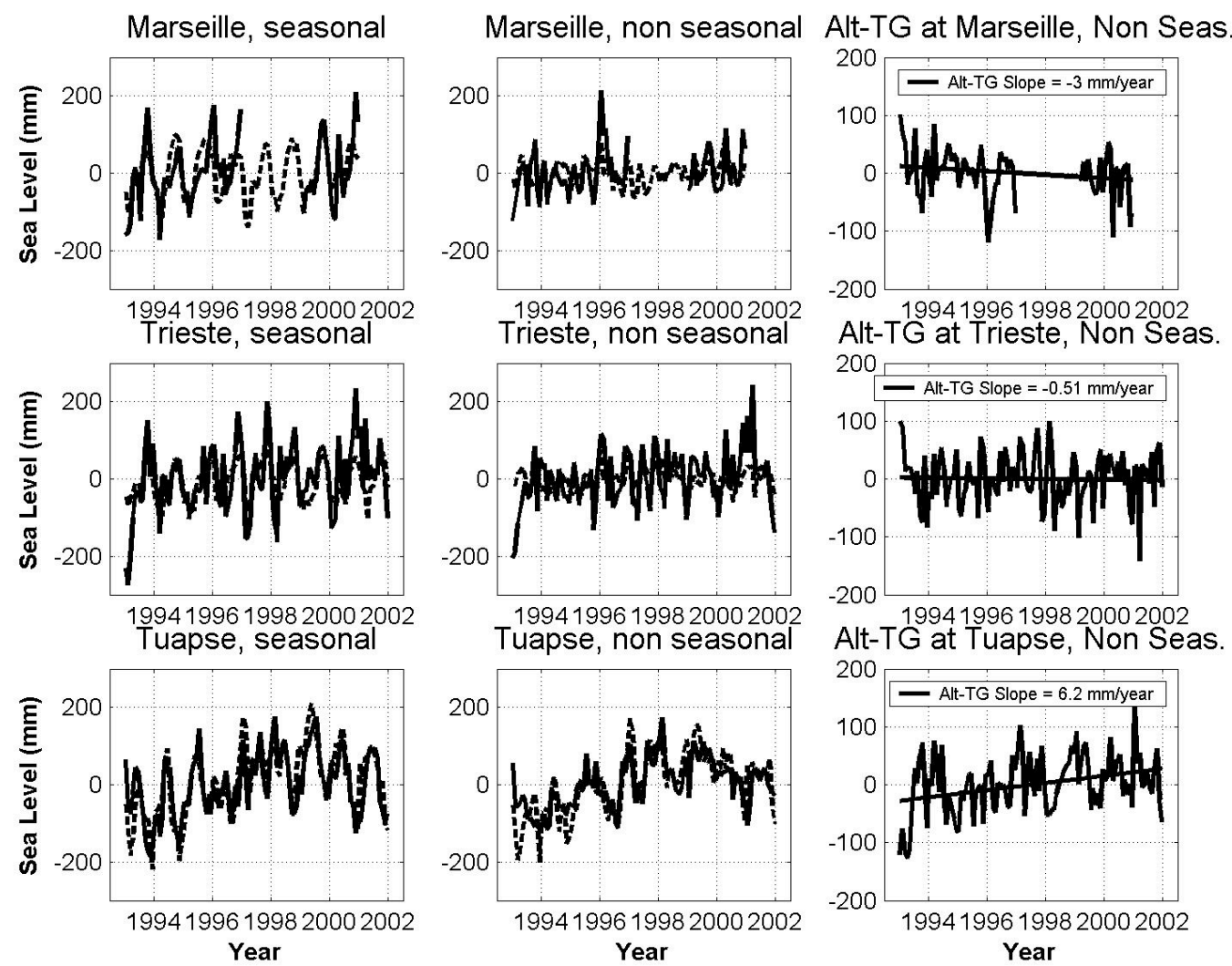
Alt-TG at Tuapse, Non Seas.

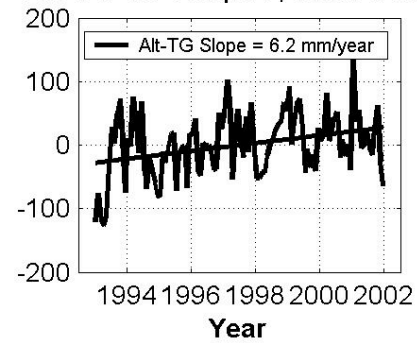

Figure 2. The first and second columns show seasonal and not seasonal Alt (solid line) and TG (dashed line) time series at Marseille (first row), Trieste (second row) and Tuapse (third row). The third column shows the non-seasonal Alt-TG time series and the least-squared linear fit to give the slope. 


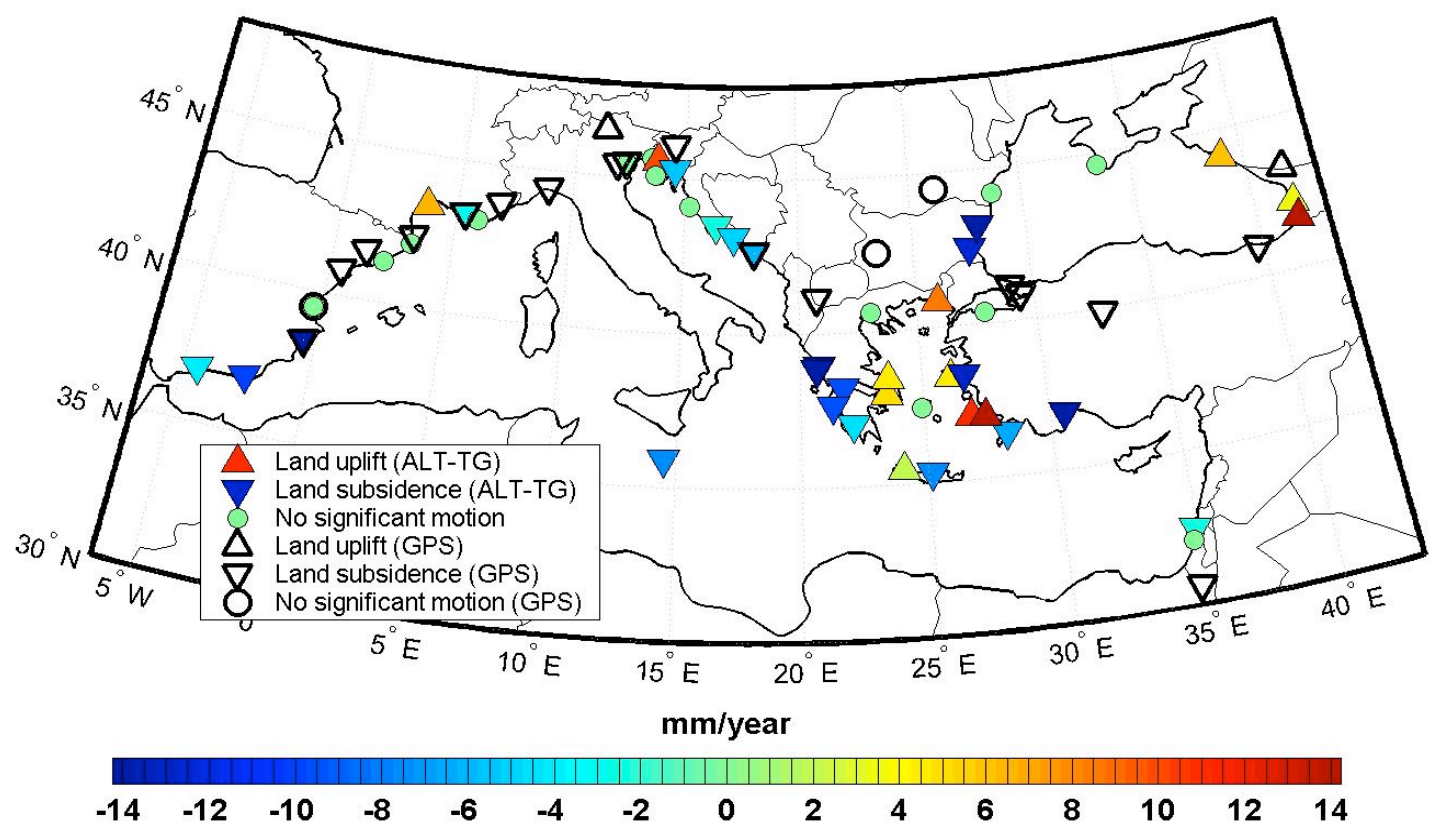

Figure 3. Vertical land movement along the Mediterranean and Black Sea coasts derived from Alt-TG time series. 


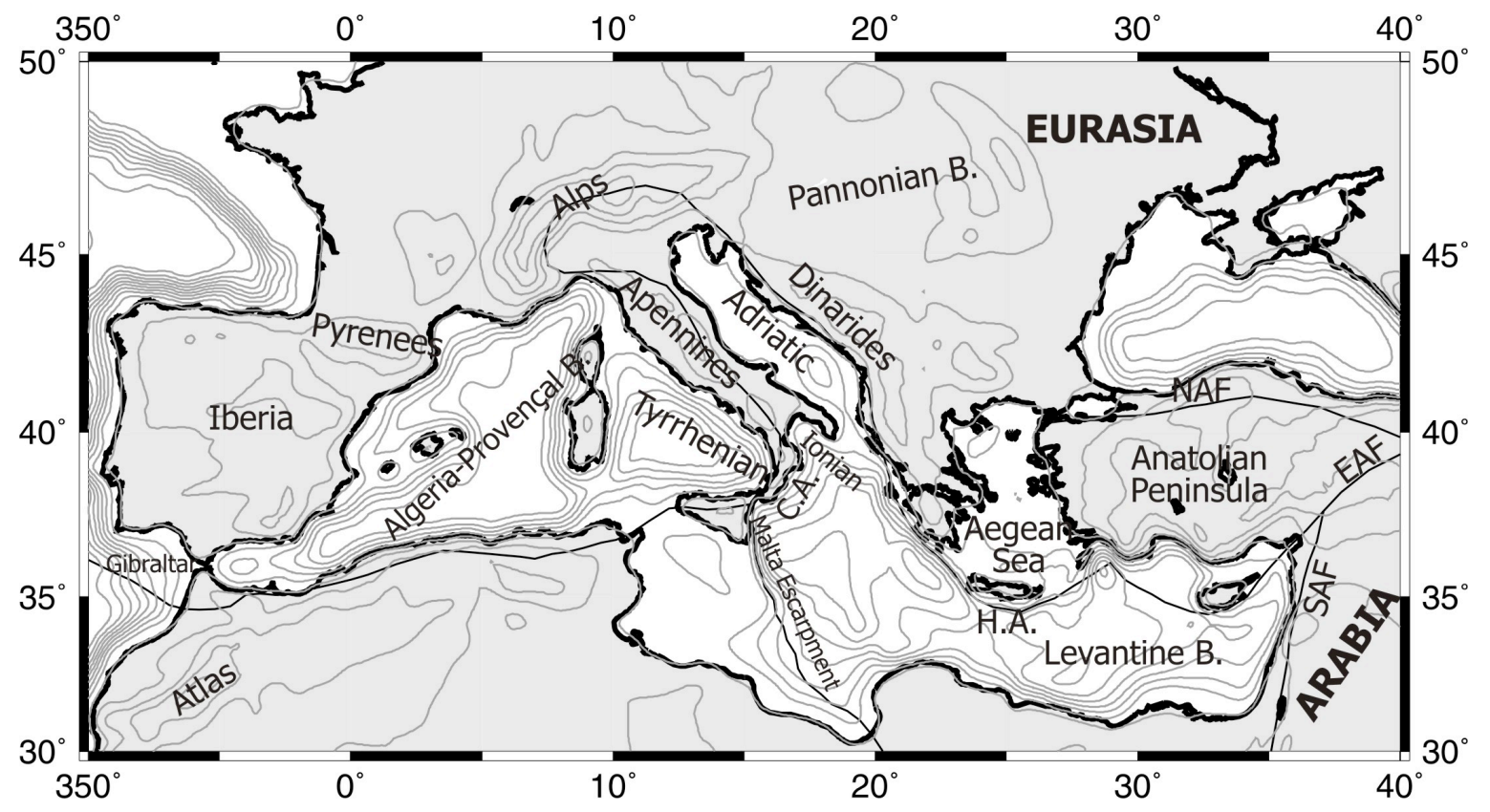

Figure 4. Black lines represent the plates boundaries in the Mediterranean and Black Seas from JIMENEZ-MUNT et al. (2003) (with permission from the author). H. A., Hellenic Arc; C. A. Calabrian Arc; B., Basin; NAF, North Anatolian Fault; SAF, South Anatolian Fault; EAF, East Anatolian Fault. Grey lines represent the topography of the region every $500 \mathrm{~m}$. Note that the grey lines on the continents are positives and those on the sea are negatives, being zero on the coast line. 


\begin{tabular}{|c|c|c|c|c|}
\hline \multicolumn{5}{|c|}{ LINEAR VCM RATE OF CHANGE (mm /year) } \\
\hline \multicolumn{5}{|c|}{ MEDITERRANEAN SEA } \\
\hline & Tide Gauge site & Location & Trend & Sigma \\
\hline 1 & Málaga ii (Spain) & $3643 \mathrm{~N} 0425 \mathrm{~W}$ & -3.8 & 2.5 \\
\hline 2 & Almería (Spain) & $3650 \mathrm{~N} 0229 \mathrm{~W}$ & -10.1 & 3.7 \\
\hline 3 & Alicante ii (Spain) & $3820 \mathrm{~N} 0029 \mathrm{~W}$ & -21.3 & 3.9 \\
\hline 4 & Valencia (Spain) & $3928 \mathrm{~N} 0020 \mathrm{~W}$ & 2.7 & 2.9 \\
\hline 5 & Barcelona (Spain) & $4121 \mathrm{~N} 0210 \mathrm{E}$ & 2.5 & 2.5 \\
\hline 6 & L’Estartit (Spain) & $4203 \mathrm{~N} 0312 \mathrm{E}$ & -0.5 & 1.9 \\
\hline 7 & Sete (France) & $4324 \mathrm{~N} 0342 \mathrm{E}$ & 6.3 & 5.2 \\
\hline 8 & Marseille (France) & $4318 \mathrm{~N} 0521 \mathrm{E}$ & -3.0 & 2.1 \\
\hline 9 & Toulon (France) & $4307 \mathrm{~N} 0555 \mathrm{E}$ & 0.9 & 1.9 \\
\hline 10 & Valletta (Malta) & $3554 \mathrm{~N} 1431 \mathrm{E}$ & -7.5 & 2.7 \\
\hline 11 & Venezia P.S. (Italy) & $4526 \mathrm{~N} 1220 \mathrm{E}$ & -0.8 & 1.9 \\
\hline 12 & Trieste (Italy) & $4539 \mathrm{~N} 1345 \mathrm{E}$ & -0.5 & 1.7 \\
\hline 13 & Luka Koper & $4534 \mathrm{~N} 1345 \mathrm{E}$ & 10.1 & 2.0 \\
\hline 14 & Rovinj (Croatia) & $4505 \mathrm{~N} 1338 \mathrm{E}$ & -2.1 & 2.3 \\
\hline 15 & Bakar (Croatia) & $4518 \mathrm{~N} 1432 \mathrm{E}$ & -5.5 & 2.6 \\
\hline 16 & Zadar (Croatia) & $4407 \mathrm{~N} 1514 \mathrm{E}$ & 3.9 & 4.0 \\
\hline 17 & Split RT Marjana & $4330 \mathrm{~N} 1623 \mathrm{E}$ & -2.1 & 2.1 \\
\hline 18 & Split Harbour & $4330 \mathrm{~N} 1626 \mathrm{E}$ & -2.4 & 2.2 \\
\hline 19 & Sucuraj (Croatia) & $4308 \mathrm{~N} 1712 \mathrm{E}$ & -5.0 & 3.0 \\
\hline 20 & Dubrovnik (Croatia) & $4240 \mathrm{~N} 1804 \mathrm{E}$ & -5.8 & 2.0 \\
\hline 21 & Preveza (Greece) & $3857 \mathrm{~N} 2046 \mathrm{E}$ & -16.8 & 2.1 \\
\hline 22 & Levkas (Greece) & $3850 \mathrm{~N} 2042 \mathrm{E}$ & -14.6 & 1.7 \\
\hline 23 & Patrai (Greece) & $3814 \mathrm{~N} 2144 \mathrm{E}$ & -9.6 & 2.0 \\
\hline 24 & Katakolon (Greece) & $3738 \mathrm{~N} 2119 \mathrm{E}$ & -9.4 & 1.8 \\
\hline 25 & Kalamai (Greece) & $3701 \mathrm{~N} 2208 \mathrm{E}$ & -4.5 & 1.7 \\
\hline 26 & North Salaminos & $3757 \mathrm{~N} 2330 \mathrm{E}$ & 4.8 & 2.0 \\
\hline 27 & Khalkis South & $3828 \mathrm{~N} 2336 \mathrm{E}$ & 9.5 & 2.2 \\
\hline 28 & Khalkis North & $3828 \mathrm{~N} 2336 \mathrm{E}$ & 4.3 & 1.6 \\
\hline 29 & Tessaloniki & $4037 \mathrm{~N} 2302 \mathrm{E}$ & 0.9 & 1.6 \\
\hline 30 & Alexandroupolis & $4051 \mathrm{~N} 2553 \mathrm{E}$ & 8.3 & 2.0 \\
\hline 31 & Khios (Greece) & $3823 \mathrm{~N} 2609 \mathrm{E}$ & 4.7 & 2.0 \\
\hline 32 & Siros (Greece) & $3726 \mathrm{~N} 2455 \mathrm{E}$ & -1.5 & 4.2 \\
\hline 33 & Leros (Greece) & $3705 \mathrm{~N} 2653 \mathrm{E}$ & 11.0 & 1.4 \\
\hline 34 & Soudhas (Greece) & $3530 \mathrm{~N} 2403 \mathrm{E}$ & 1.9 & 1.4 \\
\hline 35 & Iraklion (Greece) & $3520 \mathrm{~N} 2508 \mathrm{E}$ & -7.5 & 6.6 \\
\hline 36 & Rodhos (Greece) & $3626 \mathrm{~N} 2814 \mathrm{E}$ & -6.7 & 2.1 \\
\hline 37 & Erdek (Turkey) & $4023 \mathrm{~N} 2751 \mathrm{E}$ & -1.1 & 5.5 \\
\hline 38 & Mentes/Izmir & $3826 \mathrm{~N} 2643 \mathrm{E}$ & -12.8 & 3.8 \\
\hline 39 & Bodrum ii (Turkey) & $3702 \mathrm{~N} 2725 \mathrm{E}$ & 21.6 & 5.6 \\
\hline 40 & Antalaya ii (Turkey) & 3650 N $3037 \mathrm{E}$ & -17.6 & 4.0 \\
\hline 41 & Hadera (Israel) & $3228 \mathrm{~N} 3453 \mathrm{E}$ & -2.4 & 1.5 \\
\hline 42 & Tel Aviv (Israel) & $32053446 \mathrm{E}$ & -2.5 & 3.1 \\
\hline
\end{tabular}




\begin{tabular}{|c|l|c|c|c|}
\hline \multicolumn{5}{|c|}{ BLACK SEA } \\
\cline { 1 - 3 } 43 & Bourgas (Bulgaria) & 42 29 N 27 29 E & -12.3 & 7.4 \\
\hline 44 & Varna (Bulgaria) & 4311 N 27 55 E & -25.5 & 6.1 \\
\hline 45 & Constanza & 4410 N 28 40 E & 3.6 & 4.5 \\
\hline 46 & Sevastopol & 4437 N 33 32 E & -0.2 & 9.4 \\
\hline 47 & Tuapse (Russian & 4406 N 39 04 E & 6.2 & 1.7 \\
\hline 48 & Poti (Georgia) & 4210 N 41 41 E & 3.5 & 2.7 \\
\hline 49 & Batumi (Georgia) & 4138 N 41 42 E & 31.6 & 8.6 \\
\hline
\end{tabular}

Table 1: Linear Rate of Change, or slope, ( $\mathrm{mm} /$ year) of the Alt-TG Series. Negative values (highlighted in blue) indicate land subsidence, positive values (in red) indicate land uplift, the uncolored are values indistinguishable from zero within 1 sigma. The numbering of the sites corresponds to Figure 1. 


\begin{tabular}{|c|c|c|c|c|}
\hline \multicolumn{5}{|c|}{ VERTICAL VELOCITIES AT GPS STATIONS (mm /year) } \\
\hline \multicolumn{5}{|c|}{ MEDITERRANEAN SEA } \\
\hline & GPS site (Country) & Location & Trend & Sigma \\
\hline 1 & Alicante (Spain) & $3820 N 0029$ & -3.21 & 0.19 \\
\hline 2 & Valencia (Spain) & $3929 \mathrm{~N} 0020$ & -0.68 & 0.91 \\
\hline 3 & Ebre (Spain) & $4149 \mathrm{~N} 0030$ & -1.33 & 0.10 \\
\hline 4 & Bellmunt (Spain) & 4136 N 0124 & -0.22 & 0.18 \\
\hline 5 & Cap de Creus (Spain) & $4219 \mathrm{~N} 0318$ & -0.44 & 0.31 \\
\hline 6 & Marseille (France) & 4317 N 0521 & -2.35 & 0.16 \\
\hline 7 & Calern (France) & $4345 \mathrm{~N} 0655$ & -0.78 & 0.11 \\
\hline 8 & Genova (Italy) & $4425 \mathrm{~N} 0855$ & -1.66 & 0.21 \\
\hline 9 & Bolzano (Italy) & $4629 \mathrm{~N} 1120$ & 1.33 & 0.23 \\
\hline 10 & Venezia (Italy) & $4526 \mathrm{~N} 1220$ & -5.95 & 0.74 \\
\hline 11 & Padova (Italy) & $4524 \mathrm{~N} 0115$ & -6.32 & 0.75 \\
\hline 12 & Geoservis GR.1 (Slovenija) & $4603 \mathrm{~N} 1433$ & -1.18 & 0.96 \\
\hline 13 & Dubrovnik (Croatia) & $4239 \mathrm{~N} 1807$ & -5.31 & 0.52 \\
\hline 14 & Orhid (Macedonia) & $4108 \mathrm{~N} 2048$ & -0.68 & 0.47 \\
\hline 15 & Sofia (Bulgaria) & $4233 N 2324$ & -0.17 & 0.18 \\
\hline 16 & Mitzpe Ramon (Israel) & 3036 N 3446 & -2.25 & 0.48 \\
\hline \multicolumn{5}{|c|}{ BLACK SEA } \\
\hline 17 & Bucuresti (Romania) & $4428 \mathrm{~N} 2608$ & 0.11 & 0.18 \\
\hline 18 & Istambul (Turkey) & 4106 N 2901 & -0.52 & 0.28 \\
\hline 19 & Gebze (Turkey) & 4047 N 2927 & -4.33 & 0.23 \\
\hline 20 & Ankara (Turkey) & 3953 N 3246 & -1.70 & 0.17 \\
\hline 21 & Trabzon (Turkey) & 4100 N 3947 & -3.27 & 0.48 \\
\hline 22 & Zelenchukskava (Russia) & $4317 \mathrm{~N} 4134$ & 0.68 & 0.26 \\
\hline
\end{tabular}

Table 2: Vertical velocities (mm / year) of the GPS time series up to 1199 GPS week (late 2002). Negative values indicate land subsidence, positive values indicate land uplift. The sign of these values is represented in Figure 2. 